\title{
Life Cycle Assessment for Fiber-Reinforced Polymer (FRP) Composites Used in Concrete Beams: A State-of-the-Art Review
}

\author{
Mohamed Ibrahim \\ mohamed.amin@qu.edu.qa \\ Department of Civil and Architectural Engineering, Qatar University, Doha, Qatar \\ Usama Ebead \\ uebead@qu.edu.qa \\ Department of Civil and Architectural Engineering, Qatar University, Doha, Qatar \\ Mohammed Al-Ansari \\ m.alansari@qu.edu.qa \\ Department of Civil and Architectural Engineering, Qatar University, Doha, Qatar
}

\begin{abstract}
Fiber-reinforced polymer (FRP) composites have become popularly utilized in structural engineering applications. The common use of the FRP composites is related to their economic benefits that can be observed right away or in a long-time period. With increasing concern about global warming and the shortage of natural resources, it is essential to study the environmental implications of the use of FRP composites. Life cycle assessment (LCA) is one of the most common techniques that can be used to take the environmental impact of the FRP into consideration. This paper presents a literature review about the LCA of FRP composites in concrete beams. The LCA results reported in the literature confirmed the use of FRP composites for reinforcing the RC beams instead of conventional steel rebars or that the strengthening of $\mathrm{RC}$ beams instead of demolishing and reconstruction is a more environment-friendly approach.
\end{abstract}

Keywords: Life cycle assessment; Fiber-reinforced polymer; Reinforced concrete; Beams

\section{INTRODUCTION}

Fiber reinforcement polymer (FRP) composites have been popular within the construction industry, owing to their favorable features, including the superior durability against corrosion, versatility for in-field applications and enhanced strength-to-weight ratio as compared to their counterpart traditional materials. FRPs are commonly used for reinforcing the structural elements in place of steel reinforcement and for the structural strengthening of in-service reinforced concrete (RC) members. (Guadagnini et al., 2006, Abdel Baky et al., 2007, Kim et al., 2008, Rizzo \& Lorenzis, 2009, Chen et al., 2012, Ebead \& Saeed, 2017). Commonly, FRP composites are composed of different fiber types, such as glass FRP (GFRP), carbon FRP (CFRP), aramid FRP (AFRP), and basalt FRP (BFRP). However, the most commonly used ones are the CFRP and GFRP because of their excessive tensile strength and ductility performance, respectively. Furthermore, FRP can be made by combining varied substances to generate a hybrid FRP composite that gather the advantages of the involved materials. The FRP composites are usually used in the shape of laminates, plates, strips, sheets, and rods (rebars). The internal 
reinforcement and the external reinforcement (strengthening) of the concrete members can be easier, faster, and more effective with the use of the FRP composites. (Mohamed Ibrahim, 2019).

The growing awareness about climate change and global warming increased the attention of scholars towards analyzing the environmental impacts associated with products or services. FRP composites have some in-service environmental benefits. The light-weight of the FRP composites and its strong ability to resist corrosion enable them to decrease the energy combustion, green-house emissions associated with installation, transportation, and maintenance. However, to analyze the environmental impacts of FRP composite, it is important to consider the entire FRPs' life cycle from the raw material acquisition through production, operations until the end-of-life treatment. Life cycle assessment (LCA) is an approach used to analyze the impacts of a product or service on the environment from the stage of retrieving the raw materials from the planet until the products are recycled or wasted (Cradle-to-Gate) as per (International Organisation for Standardisation, 2006). The capability of LCA in analyzing the impacts of the industrial systems on the environment is broader and more comprehensive, compared to other cycles, where each stage is considered alone and the interrelation of the products with other activities is ignored. LCA enables the evaluation of a product's impact on global warming (mainly the $\mathrm{CO}_{2}$ emissions), ozone depletion, eco-systems, energy consumption and human toxicity. Figure 1 shows the flow process of LCA as per the International Organisation for Standardisation (2006).

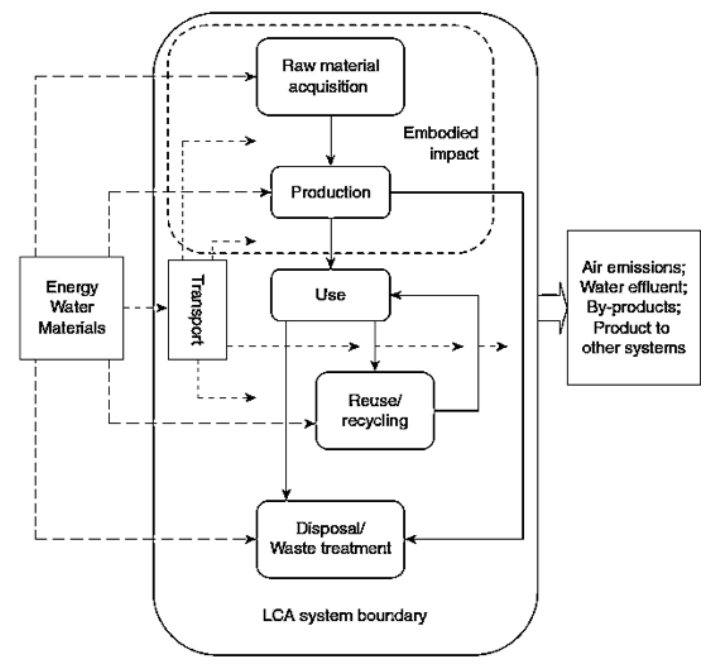

Figure 1: Flow process of LCA (International Organisation for Standardisation, 2006)

The process of practicing a LCA is considered a systematic approach, which consists of four phases: Goal Definition; Inventory Analysis; Impact Assessment; and Interpretation of Results (Zhang, 2013). The Goal Definition phase includes defining the scope of the assessment by clearly defining the boundaries that are in the scope of interest and the environmental effects which are considered in the assessment of the defined product or service. The Inventory Analysis phase is about the quantification 
of the product's material and energy usages throughout its life cycle, such as carbon dioxide $\mathrm{CO}_{2}$ emissions, solid waste disposal, and wastewater discharges. The Impact Assessment phase includes the use of the data in the inventory analysis to assess the impact of the product on several aspects of the environment such as human toxicity, ozone depletion, global warming, Acidification potential and Eutrophication potential. However, the scope of the LCA will define what impacts are going to be considered in the analysis. In the Interpretation of Results phase, the assessments of the emissions and energy usage due to the production of the material in its life cycle are evaluated. The evaluation provides a clear interpretation and understanding of the environmental impacts associated with the product under study. The four components of the LCA are summarized in Figure 2. In the literature, there are several LCA studies about using the FRP composites in the construction applications (Bakis, 2009, Russell-Smith \& Lepech, 2009, Mara et al., 2013, Zhang, 2013, Dong et al., 2015, Inman et al., 2017, Cadenazzi et al., 2019, Van Loon et al., 2019).

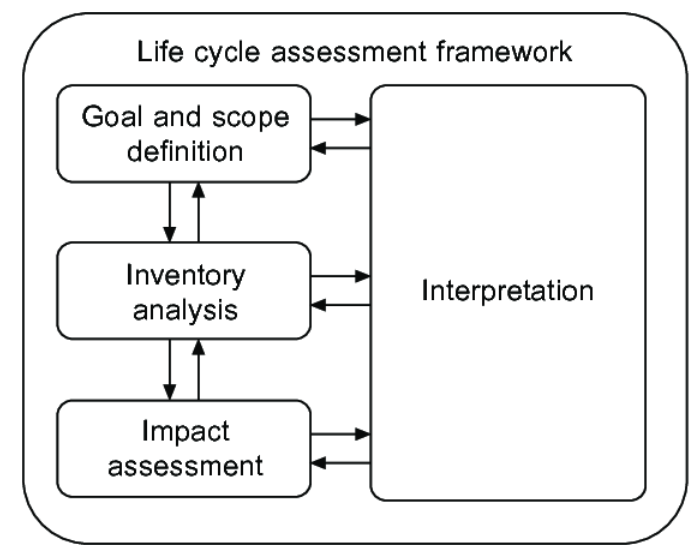

Figure 2: LCA Framework (based on ISO, 2006)

This paper aims to explore the results of existing literature about the environmental impact of using FRP composites in concrete beams either to replace the internal reinforcement (steel rebars) or to strengthen the $\mathrm{RC}$ beams by external reinforcement.

\section{LCA OF FRP REINFORCED CONCRETE BEAMS}

This section provides the environmental impact of using the FRP rebars for reinforcing the concrete structural elements instead of steel rebars, as summarized in Table 1. Garg and Shrivastava (2019) have conducted an analytical study to compare the $\mathrm{CO}_{2}$ emission and energy consumption resulting from using three types of FRP rebars (CFRP, GFRP, and BFRP) to replace the traditional steel reinforcement rebars for rectangular concrete beams. The LCA environmental impact is determined using Cradle-to-Gate data of each type of reinforcement. Generally, the results showed that the FRP rebars have a better impact on the environment than that of steel rebars. In terms of $\mathrm{CO}_{2}$ emissions, the GFRP, BFRP, and CFRP reinforced beams showed $43 \%, 40 \%$, and $39 \%$ less $\mathrm{CO}_{2}$ emissions compared to the steel reinforced beams, respectively, as shown in Figure 3. In terms of energy consumption, the GFRP, BFRP, and CFRP reinforced beams showed 
$47 \%, 50 \%$, and $32 \%$ less energy consumption than that with steel reinforced beams, respectively as shown in Figure 3. Van Loon et al. (2019) have conducted research to reduce the environmental-economic (shadow) costs of precast RC beams. The authors have studied the impact of partial replacement of the conventional steel rebars by FRP tubes. The authors have considered FRP tubes made of different types of fibers namely, E-glass, Flax, and Kenaf. Results revealed that replacing $46 \%, 46 \%$ and $39 \%$ of the steel reinforcement by E-glass, Flax, and Kenaf FRP decreases the shadow costs by $28 \%, 39 \%, 36 \%$ keeping the capacity unaltered, respectively (Figure 4). Inman et al. (2017)Inman et al. (2017) have performed mechanical and environmental assessments to compare the BFRP rebars and steel rebars in the concrete beams. The results showed that there is $62 \%$ saving in the $\mathrm{CO} 2$ emissions when the BFRP reinforcement was chosen over the conventional steel rebars. In terms of ozone depletion, and human toxicity, the use of BFRP rebars showed an average reduction of $21 \%$ and $78 \%$, respectively. The authors have also studied other environmental impacts such as Terrestrial acidification, Freshwater eutrophication, Marine eutrophication, Photochemical oxidant, Formation, Particulate matter formation, Terrestrial eco-toxicity, Agricultural land Occupation, and Natural land transformation. The results of these environmental impacts were observed to be minimal or less important.

Table 1: Comparison of LCA results from different studies of replacement of the conventional steel reinforcement by FRP composites

\begin{tabular}{|c|c|c|c|c|}
\hline Reference & $\begin{array}{c}\text { Type of } \\
\text { FRP } \\
\text { placement } \\
\text { Rebars }\end{array}$ & $\begin{array}{c}\text { FRP Re- } \\
\text { Environmental Impact } \\
\text { Category }\end{array}$ & $\begin{array}{c}\text { Reduction } \\
\% \text { in the } \\
\text { Environmental } \\
\text { impact due to } \\
\text { using FRP rebars }\end{array}$ \\
\hline $\begin{array}{c}\text { Garg and Shrivastava, } \\
(2019)\end{array}$ & GFRP & $100 \%$ & Global Warming $\left(\mathrm{CO}_{2}\right.$ emissions) & $43 \%$ \\
\hline $\begin{array}{c}\text { Garg and Shrivastava, } \\
(2019)\end{array}$ & GFRP & $100 \%$ & Energy Consumption & $47 \%$ \\
\hline $\begin{array}{c}\text { Garg and Shrivastava, } \\
(2019)\end{array}$ & BFRP & $100 \%$ & Global Warming $\left(\mathrm{CO}_{2}\right.$ emissions) & $40 \%$ \\
\hline $\begin{array}{c}\text { Garg and Shrivastava, } \\
(2019)\end{array}$ & BFRP & $100 \%$ & Energy Consumption & $50 \%$ \\
\hline $\begin{array}{c}\text { Garg and Shrivastava, } \\
(2019)\end{array}$ & CFRP & $100 \%$ & Global Warming (CO emissions) & $39 \%$ \\
\hline $\begin{array}{c}\text { Garg and Shrivastava, } \\
(2019)\end{array}$ & CFRP & $100 \%$ & Energy Consumption & $32 \%$ \\
\hline Van Loon et al. (2019) & E-glass & $46 \%$ & Shadow Cost & $28 \%$ \\
\hline Van Loon et al. (2019) & Flax & $46 \%$ & Shadow Cost & $39 \%$ \\
\hline Van Loon et al. (2019) & Kenaf & $39 \%$ & Shadow Cost & $36 \%$ \\
\hline Inman et al. (2017) & BFRP & $100 \%$ & Global Warming (CO 2 emissions) & $62 \%$ \\
\hline Inman et al. (2017) & BFRP & $100 \%$ & Ozone Depletion & $21 \%$ \\
\hline Inman et al. (2017) & BFRP & $100 \%$ & Human Toxicity & $78 \%$ \\
\hline
\end{tabular}




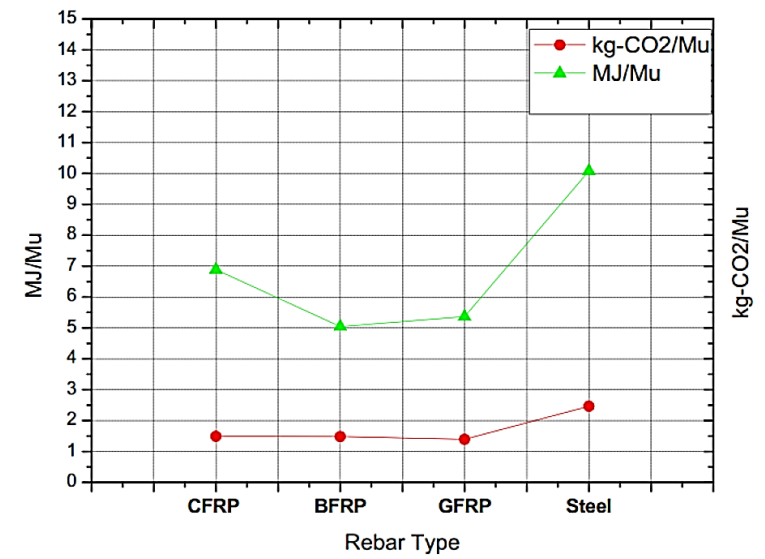

Figure 3: LCA results in terms of energy consumption (at the left side) and the $\mathrm{CO}_{2}$ emissions (at the right side) for different types of reinforcement rebars in concrete beams, as per (Garg \& Shrivastava, 2019)

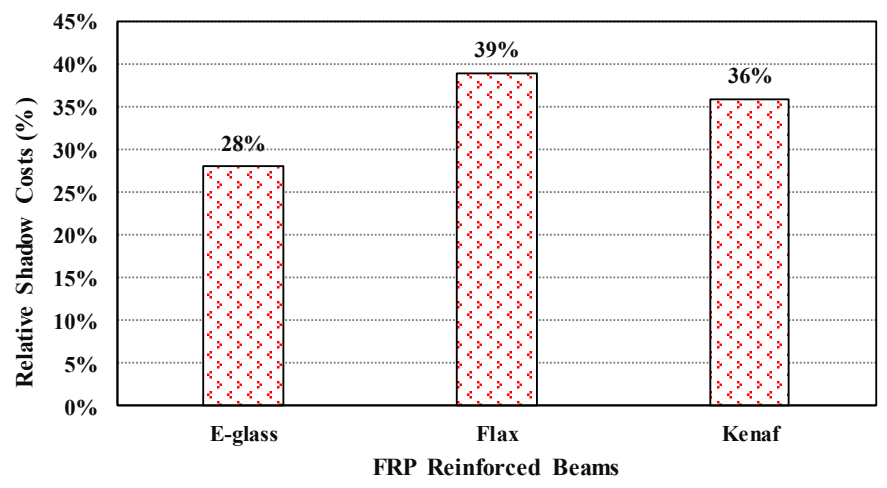

Figure 4: Reduction \% of using E-glass, Flax, and Kenaf FRP tubes as partial replacement to the conventional steel rebars (Van Loon et al., 2019)

\section{LCA OF FRP USED FOR STRENGTHENING OF RC STRUCTURES}

There are various causes of the deterioration of the RC structures including the excessive corrosion of steel reinforcement (especially in the severe weather regions), improper or flawed maintenance, unaccounted carrying load augmentation, increase of the life service load, changing of the original structure's purpose, and mistakes on the design or construction development. Deteriorated and deficient structures require an effective and immediate strengthening application to ensure the users' safety. Strengthening and rehabilitation can be an economical and environmentally possible alternative to demolition/reconstruction of the deteriorated and deficient structures. In the construction sector, FRP can be used for strengthening of existing buildings, thus creating the possibility of avoiding the environmental problems resulting from demolishing these structures and constructing new ones. Several studies have investigated the LCA using FRP composites for the strengthening of RC beams compared to demolish and 
reconstruction, as summarized in Table 2. Maxineasa et al. (2015) conducted a LCA to compare the environmental impacts resulting from the strengthening of an existing RC beam with FRP and the environmental impacts resulting from constructing a new RC beam. The study includes different strengthening techniques using CFRP strips. The authors used the cradle-to-gate LCA type to assess the impact categories, namely, global warming, human toxicity, and ozone depletion. Results releveled that the strengthening techniques using FRP can increase the ultimate capacity of the RC beam from $60 \mathrm{kN}$ to $184.3 \mathrm{kN}(207 \%)$. Moreover, the total $\mathrm{CO}_{2}$ emissions resulting from the strengthening process was reported $69 \%$ less than that for constructing a new RC beam. Similarly, the reduction in the human toxicity and the ozone depletion were reported $73 \%$ and $48 \%$ compared to the reference beam, respectively. These results were confirmed by (Palacios-Munoz et al., 2018). The authors have reported that the total $\mathrm{CO}_{2}$ emissions due to strengthening the RC beam by CFRP and due to demolishing and reconstruction new RC beam through a comparative LCA study. The authors observed a $65 \%$ reduction in the $\mathrm{CO}_{2}$ emission from the strengthened beam than that from the reconstructed beam. Maxineasa et al. (2018) have compared the total $\mathrm{CO}_{2}$ emissions resulting from the construction $\mathrm{RC}$ beam and the environmental impact resulting from strengthening an existing RC beam using CFRP and GFRP. The LCA study was Cradle-to-Gate type for the involved materials in global warming $\left(\mathrm{CO}_{2}\right.$ emissions $)$ and the ozone depletion. The authors reported $76 \%$ and $67 \%$ lower in the $\mathrm{CO}_{2}$ emissions due to strengthening by GFRP and CFRP, compared to the $\mathrm{CO}_{2}$ emissions resulting from construction of new $\mathrm{RC}$ beams, respectively. In addition, the ozone depletion was reduced by $14.2 \%$ by using both FRP types.

Table 2: Comparison of LCA results from different studies about the strengthening of inservice RC structures compared to demolishing and reconstruction of new RC structure

\begin{tabular}{|l|l|l|l|l|}
\hline & $\begin{array}{l}\text { Type of } \\
\text { RRP }\end{array}$ & $\begin{array}{l}\text { Increase } \% \text { in the } \\
\text { load-carrying capacity } \\
\text { due to strengthening }\end{array}$ & $\begin{array}{l}\text { Environmental Impact } \\
\text { Category }\end{array}$ & $\begin{array}{l}\text { Reduction \% in the } \\
\text { Environmental impact } \\
\text { due to Strengthening }\end{array}$ \\
\hline Maxineasa et al. (2015) & CFRP & $207 \%$ & $\begin{array}{l}\text { Global Warming }\left(\mathrm{CO}_{2}\right. \\
\text { emissions) }\end{array}$ & $69 \%$ \\
\hline Maxineasa et al. (2015) & CFRP & $207 \%$ & Human Toxicity & $73 \%$ \\
\hline Maxineasa et al. (2015) & CFRP & $207 \%$ & Ozone Depletion & $48 \%$ \\
\hline Palacios-Munoz et al. (2018) & CFRP & $50 \%$ & $\begin{array}{l}\text { Global Warming }\left(\mathrm{CO}_{2}\right. \\
\text { emissions })\end{array}$ & $72 \%$ \\
\hline Palacios-Munoz et al. (2018) & CFRP & $50 \%$ & Energy Consumption & $60 \%$ \\
\hline Maxineasa et al. (2018) & GFRP & N/A & $\begin{array}{l}\text { Global Warming }\left(\mathrm{CO}_{2}\right. \\
\text { emissions) }\end{array}$ & $73 \%$ \\
\hline Maxineasa et al. (2018) & GFRP & N/A & Ozone Depletion & $14.2 \%$ \\
\hline Maxineasa et al. (2018) & CFRP & N/A & $\begin{array}{l}\text { Global Warming }\left(\mathrm{CO}_{2}\right. \\
\text { emissions) }\end{array}$ & $14.2 \%$ \\
\hline Maxineasa et al. (2018) & CFRP & N/A & Ozone Depletion & $66 \%$ \\
\hline
\end{tabular}

\section{CONCLUSION AND RECOMMENDATIONS}

This paper has provided a literature review on the LSA for FRP composites that have been used either for reinforcing concrete beams instead of the conventional steel rebars or for strengthening the old RC beams instead of demolishing and reconstruction of new 
ones. Overall, the results reported in the existing literature were found to be consistent with each other and confirming that the utilization of FRP composites is a preferable approach towards reducing the environmental impacts. From the literature, the most important environmental impacts that are commonly assessed are the potential of global warming due to $\mathrm{CO}_{2}$ emissions, the ozone layer potential, and the human toxicity potential through the life cycle of the product e.g., FRP. Although several scholars have investigated the LCA of FRP in RC structures, the literature still lacks in this context. A limited number of LSA studies have been conducted on replacing the steel rebars of completed structural building projects. Moreover, some authors have not mentioned the increase in percentage due to strengthening although it is essential to assess the performance of FRP with their environmental impact. Therefore, the authors of this paper recommend conducting a comprehensive LSA of using GFRP, CFRP and BFRP rebars as a replacement to the conventional steel rebars for various structural members' designs such as columns, beams, slabs and footings for completed RC high-rise building projects. Furthermore, the authors recommend enriching the literature by conducting a grade-to-gate LCA of using different strengthening techniques such as near-surface mounted and near-surface embedded, using different types of FRP namely, rods, sheets, or laminates for strengthening RC structural members. Finally yet importantly, authors suggest exploring the interaction between the economic impacts and the environmental impacts of the use of FRP in the concrete structural elements in order to help the decisionmakers with a widespread overview.

\section{REFERENCES}

Abdel Baky, H., Ebead, U. A. \& Neale, K. W. (2007). Flexural and interfacial behavior of FRP-strengthened reinforced concrete beams. Journal of Composites for Construction, 11 (December), 629-639.

Bakis, C. E. (2009). Life cycle analysis issues in the use of Frp composites in civil infrastructure. Life Cycle Assessment of Sustainable Infrastructure Materials, 21-22.

Cadenazzi, T., Dotelli, G., Rossini, M., Nolan, S. \& Nanni, A. (2019). Life-cycle cost and lifecycle assessment analysis at the design stage of a fiber-reinforced polymer-reinforced concrete bridge in Florida. Advances in Civil Engineering Materials, 8(2), 20180113.

Chen, G. M., Chen, J. F. \& Teng, J. G. (2012). On the finite element modelling of RC beams shear-strengthened with FRP. Construction and Building Materials, 32, 13-26.

Dong, J. F., Jia, P., Yuan, S. C. \& Wang, Q. Y. (2015). Compressive behaviours of square timber columns reinforced by partial wrapping of FRP sheets. Materials Research Innovations, 19, S1465-S1468.

Ebead, U. \& Saeed, H. (2017). FRP/stirrups interaction of shear-strengthened beams. Materials and Structures/Materiaux et Constructions, 50(2), 1-16.

Garg, N. \& Shrivastava, S. (2019). Environmental and economic comparison of frp reinforcements and steel reinforcements in concrete beams based on design strength parameter. In: Dr B $\mathrm{R}$ Ambedkar National Institute of Technology, ed. UKIERI Concrete Congress, Jalandhar (Punjab), India.

Guadagnini, M., Pilakoutas, K. \& Waldron, P. (2006). Shear Resistance of FRP RC Beams: Experimental Study. Journal of Composites for Construction, 10(6), 464-473. 
Inman, M., Thorhallsson, E. R. \& Azrague, K. (2017). A Mechanical and Environmental Assessment and Comparison of Basalt Fibre Reinforced Polymer (BFRP) Rebar and Steel Rebar in Concrete Beams. Energy Procedia, 111(1876), 31-40.

International Organisation for Standardisation, (2006). Environmental management - Life cycle assessment-Principles and framework. ISO 14040. Geneva, Switzerland.

Kim, G., Sim, J. \& Oh, H. (2008). Shear strength of strengthened RC beams with FRPs in shear. Construction and Building Materials, 22(6), 1261-1270.

Van Loon, R. R. L., Pujadas-Gispert, E., Moonen, S. P. G. \& Blok, R. (2019). Environmental optimization of precast concrete beams using fibre reinforced polymers. Sustainability (Switzerland), 11(7).

Mara, V., Haghani, R., Sagemo, A., Storck, L. \& Nilsson, D. (2013). Comparative study of different bridge concepts based on life-cycle cost analyses and life-cycle assessment. Proceedings of the 4th Asia-Pacific Conference on FRP in Structures, APFIS 2013, 1-6.

Maxineasa, S. G., Isopescu, D. N., Entuc, I. S., Taranu, N., Lupu, L. M. \& Hudisteanu, I. (2018). Environmental performances of different carbon and glass fibre reinforced polymer shear strengthening solutions of linear reinforced concrete, $11(1)$.

Maxineasa, S. G., Taranu, N., Bejan, L., Isopescu, D. \& Banu, O. M. (2015). Environmental impact of carbon fibre-reinforced polymer flexural strengthening solutions of reinforced concrete beams. International Journal of Life Cycle Assessment, 20(10), 1343-1358.

Mohamed Ibrahim (2019). Externally Bonded and Near-surface Mounted FRP Strips For Shear Strengthening of RC Deep Beams. Qatar University.

Palacios-Munoz, B., Gracia-Villa, L., Zabalza-Bribián, I. \& López-Mesa, B. (2018). Simplified structural design and LCA of reinforced concrete beams strengthening techniques. Engineering Structures, 174 (July), 418-432.

Rizzo, A. \& Lorenzis, D. L. (2009). Behavior and capacity of RC beams strengthened in shear with NSM FRP reinforcement. Construction and Building Materials, 23(4), 1555-1567.

Russell-Smith, S. V \& Lepech, M. D. (2009). Life cycle assessment of frp seismic retrofitting. Life Cycle Assessment of Sustainable Infrastructure Materials, 21-22.

Zhang, C. (2013). Life cycle assessment (LCA) of fibre reinforced polymer (FRP) composites in civil applications. Eco-Efficient Construction and Building Materials: Life Cycle Assessment (LCA), Eco-Labelling and Case Studies, 565-591. 